\title{
Reported traumatic injuries among West Coast Dungeness crab fishermen, 2002-2014
}

\section{Samantha Case ${ }^{1}$, Viktor Bovbjerg ${ }^{2}$, Devin Lucas ${ }^{1}$, Laura Syron², Laurel Kincl ${ }^{2}$}

${ }^{1}$ National Institute for Occupational Safety and Health, Western States Division, Alaska Office, Anchorage, Alaska, United States ${ }^{2}$ College of Public Health and Human Sciences, School of Biological and Population Health Sciences,

Oregon State University, Corvallis, Oregon, United States

\begin{abstract}
Background: Commercial fishing is a high-risk occupation. The West Coast Dungeness crab fishery has a high fatality rate; however, nonfatal injuries have not been previously studied. The purpose of this report was to describe the characteristics of fatal and nonfatal traumatic occupational injuries and associated hazards in this fleet during 2002-2014.

Materials and methods: Data on fatal injuries were obtained from a surveillance system managed by the National Institute for Occupational Safety and Health. Data on nonfatal injuries were manually abstracted from Coast Guard investigation reports and entered into a study database. Descriptive statistics were used to characterise demographics, injury characteristics, and work processes performed.

Results: Twenty-eight fatal and 45 nonfatal injuries were reported between 2002 and 2014 in the Dungeness crab fleet. Most fatalities were due to vessel disasters, and many nonfatal injuries occurred on-deck when fishermen were working with gear, particularly when hauling the gear (47\%). The most frequently reported injuries affected the upper extremities (48\%), and fractures were the most commonly reported injury type (40\%). The overall fatality rate during this time period was 209 per 100,000 full-time equivalent workers and the rate of nonfatal injury was 3.4 per 1,000 full-time equivalent workers.

Conclusions: Dungeness crab fishermen are at relatively high risk for fatal injuries. Nonfatal injuries were limited to reported information, which hampers efforts to accurately estimate nonfatal injury risk and understand fishing hazards. Further research is needed to identify work tasks and other hazards that cause nonfatal injuries in this fleet. Engaging fishermen directly may help develop approaches for injury prevention.
\end{abstract}

(Int Marit Health 2015; 66, 4: 207-210

Key words: commercial fishing, occupational safety, injuries

\section{INTRODUCTION}

Commercial fishing remains one of the highest-risk occupations in the United States, with a fatality rate nearly 23 times greater than that of all workers [1]. Research has found that some fleets have higher risks than others due to specific hazards associated with fishing gear, operating season, and location. In the United States, the Dungeness crab fishery has been identified as hazardous for risk of fatal injuries [2, 3].

The West Coast Dungeness crab fishery is economically significant, with 52.8 million pounds landed generating \$177 million in revenue in 2012 [4]. Approximately 3,200 captains and deckhands participate in this fishery [5]. Fishing operations are conducted close to shore in shallow waters, exposing fishermen to treacherous weather and surf conditions, particularly during the winter season opening. Using hydraulic blocks, crews can set and haul hundreds of pots each day $[6,7]$.

Commercial fishing safety research in the United States has primarily focused on the epidemiology of fatal injuries. The literature on nonfatal injury research in the industry is limited to a few specific fisheries, regions, or injury types [8]. Nonfatal injuries in the West Coast Dungeness crab fleet have not been studied. These injuries may be life-threat-

Samantha Case, MPH, National Institute for Occupational Safety and Health, Western States Division, Alaska Office, 4230 University Dr. Ste 310, Anchorage, AK 99508, tel: (907)-271-1569, fax: (907)-271-2390, e-mail: scase@cdc.gov 
ening or life-altering, resulting in long-term disability, decreased quality of life, lost wages, and lower productivity; thus, examining the burden of nonfatal injuries in this fleet is imperative to improving the health and safety of fishermen. The purpose of this study was to characterise traumatic injuries in the West Coast Dungeness crab fleet, with an emphasis on nonfatal injuries. These results will inform future research on nonfatal injuries, including the development of targeted intervention strategies.

\section{MATERIALS AND METHODS}

This study examined all fatal and nonfatal work-related traumatic injuries among commercial Dungeness crab fishermen in California, Oregon, and Washington that were reported to the United States Coast Guard (USCG) during 2002-2014. Traumatic injuries were defined as "any wound or damage to the body resulting from acute exposure to energy... or from the absence of such essentials as heat or oxygen, caused by a specific event or incident" [9]. IIInesses and chronic ailments, including pre-existing medical conditions or repetitive motion injuries, were not included. While at sea, any loss of life or injury requiring more than first aid treatment must be reported to the USCG as required under 46 CFR §4.05-1 [10]. Fishermen were considered at work any time while at sea, even if off duty.

Data on fatal injuries were obtained from the National Institute for Occupational Safety and Health Commercial Fishing Incident Database, which includes data on all fatal work-related injuries in the fishing industry [3].

Data collection for nonfatal traumatic injury information was conducted through a process of reviewing and abstracting information from USCG investigation reports, coding relevant data, and entering the data into a study database. Variables of interest included incident location, weather conditions, contributing factors, demographics, work process, injury characteristics, and vessel characteristics. Work process codes were based on those developed by Jensen et al. [11] and adapted for the fleet. Injury coding included Occupational Injury and IIIness Classification System codes for nature and body part affected, as well as the Abbreviated Injury Scale (AIS) for severity, ranging from minor to severe, as described previously [12].

A descriptive analysis was completed to explore patterns of injuries. Percent distributions for individual variables excluded cases with missing data (i.e., casewise deletion). Injury rates were calculated using full-time equivalent (FTE) workforce data [5]. Because FTE data for 2013 and 2014 were unavailable, the 2012 figures were extended as estimates for those years.

\section{RESULTS}

During 2002-2014, 28 fatal injuries occurred among Dungeness crab fishermen in California, Oregon, and
Washington, averaging approximately 2 fatalities per year. The number of fatalities each year remained relatively constant; however, there was a high of 7 fatalities in the fishery in 2006, due to 2 vessel disasters in which all crewmembers perished. The majority of fatalities $(20,71 \%)$ were caused by drowning or trauma during 13 vessel disasters (e.g., capsizing or sinking). Most of these events were related to poor weather conditions (10/13, 77\%). None of the fishermen who died during a vessel disaster were able to don immersion suits or enter a life raft. Based on the narratives describing the vessel disasters, the rapid onset of events left survival gear out of reach. The remaining 8 (29\%) deaths were caused by drowning after falling overboard. None of these victims were wearing a personal flotation device when they drowned. The rate of fatal injuries during this time period was 209 deaths per 100,000 FTEs.

Forty-five nonfatal injuries were reported to the USCG, a rate of 3.4 nonfatal injuries per 1,000 FTEs. Annually, during this time period, the number of injuries ranged from 0 in 2005 to a maximum of 7 in 2007 with no trend. Most injuries occurred on board $(31,69 \%)$. Other injuries occurred while crewmembers were abandoning ship $(13,29 \%)$. Over half of the incidents occurred in the waters of Oregon $(23,56 \%)$, with the remaining occurring in the waters of Washington (12, 29\%) and California (6, 15\%).

The majority of injured crewmembers were deckhands $(37,88 \%)$, followed by captains $(5,12 \%)$. The median age of those injured was 35 years (range 20-56 years) and victims had varying levels of fishing experience (median 10 years, range $0-37$ years). All injured fishermen were male.

Fractures were the most commonly reported injury (17, 40\%). Hypothermia was reported for 7 fishermen due to fall overboard or vessel disaster (16\%), followed by lacerations (6,14\%), digit amputations $(5,12 \%)$, and sprains $(5,12 \%)$. Upper extremities $(21,48 \%)$ were the most frequently affected body parts and were most often fractures $(8,42 \%)$, amputations $(5,26 \%)$, and lacerations $(4,21 \%)$. Nearly half of all nonfatal injuries were classified as moderate $(20,47 \%)$, followed by serious $(14,33 \%)$ and minor $(8,19 \%)$. Only 1 fisherman sustained severe injuries, and none were classified as critical. Most of the injuries classified as serious or severe were fractures (10,67\%).

Injuries occurred most frequently while fishermen were hauling gear (18, 47\%), handling gear on deck $(6,16 \%)$, and preparing fishing gear $(4,11 \%)$. When hauling fishing gear, fishermen were injured while operating the block, guiding and landing pots, emptying crabs from pots, and attaching lines. The upper extremities were most at risk for injury while performing these tasks $(11,61 \%)$. Injury severity while hauling gear was predominantly classified as moderate $(10,56 \%)$ or serious $(5,28 \%)$ (Table 1 ). 
Table 1. Work process and severity of injury for nonfatal traumatic injuries among Dungeness crab fishermen reported to the United States Coast Guard, 2002-2014

\begin{tabular}{lllllll}
\hline Work process & \multicolumn{2}{l}{ Severity of injury } & & & \\
\cline { 2 - 6 } & Minor & Moderate & Serious & Severe & Missing & Total \\
\hline Watch & 0 & 3 & 0 & 0 & 0 & 3 \\
Preparing fishing gear & 1 & 1 & 2 & 0 & 0 & 4 \\
Shooting/setting the gear & 0 & 1 & 0 & 0 & 0 & 1 \\
Hauling the gear & 2 & 10 & 5 & 1 & 0 & 18 \\
Handling gear on deck & 3 & 1 & 2 & 0 & 0 & 6 \\
Other work with the catch & 0 & 0 & 1 & 0 & 0 & 1 \\
Working in engine room & 0 & 1 & 1 & 0 & 0 & 2 \\
Mooring & 0 & 1 & 0 & 0 & 0 & 1 \\
Off duty & 1 & 0 & 0 & 0 & 0 & 1 \\
Other & 0 & 0 & 1 & 0 & 0 & 1 \\
Missing & 1 & 2 & 2 & 0 & 2 & 7 \\
Total & 8 & 20 & 14 & 1 & 2
\end{tabular}

\section{DISCUSSION}

Consistent with previous studies [2, 3], the fatality rate for the West Coast Dungeness crab fleet (209 deaths per 100,000 FTEs during 2002-2014) was several times higher than the national rate for the commercial fishing industry (75 deaths per 100,000 FTEs in 2013) [1]. Differences in denominator calculations limit the ability to directly compare the fatality rate with international rates [13]. Due to the high proportion of deaths due to vessel disasters, a continued need for vessel safety programs is evident. Previously, vessels in the fleet could voluntarily participate in Operation Safe Crab, a USCG program developed in 2000 to ensure vessels maintain certain safety standards (e.g., watertight integrity and vessel stability) and carry lifesaving equipment. Findings from an evaluation of Operation Safe Crab to determine its effect on preventing fatal events were inconclusive [6]. The study found that Operation Safe Crab attempted to target the most at-risk vessels at various ports; consequently, the number of vessels enrolled in the programme was lower than anticipated, limiting the statistical analysis. The data from this study were not sufficient to determine the effect of Operation Safe Crab. However, continued participation in dockside examinations is recommended as the checks may improve a crew's chance of survival if a vessel disaster occurs. In addition to having survival equipment available, it is essential that fishermen are trained for emergencies and in using the gear. Crews should participate in survival trainings, as well as conduct emergency response drills on board regularly to familiarise themselves with abandonment procedures $[14,15]$.

Examining nonfatal injuries including the work process allowed for identification of tasks most frequently associat- ed with injury. Working directly with fishing gear, including hauling, preparing, or other handling of gear, contributed to the majority of injuries that occurred on board. Fractures were commonly reported during these tasks and made up the majority of the most serious injuries, highlighting the hazards of working with crab pots and hydraulic blocks.

While the rate of fatal injuries was 65 times higher than the rate for all United States workers, the nonfatal injury rate was 3 times lower than the rate for all United States workers $[1,16]$. The rate of nonfatal injuries calculated in this study was also much lower than reported for the Alaska freezer-longliner fleet (10 times lower) and freezer-trawl fleet (13 times lower) [12]. However, these freezer fleets are enrolled in a particular USCG programme that actively encourages reporting. Additionally, the nonfatal injury rate among Dungeness crab fishermen was 3 times lower than reported for commercial fishermen in New Jersey, although fleet-specific rates were not available for comparison [17]. The rate of nonfatal injuries within the Dungeness crab fleet is likely an underestimate. In general, underreporting of occupational injuries from employers has been linked to concerns of financial and regulatory repercussions, and the burden of reporting itself may be a barrier [18]. In particular, less severe injuries are likely to be underreported or simply not captured using existing surveillance systems $[18,19]$. The implication is that valid, comparable estimates of injury risk, as well as specific hazards are not possible using data on reported injuries alone, unless reporting of nonfatal injuries becomes standard practice. Improving the reporting by fishermen is needed to better understand the burden of injury and opportunity for injury prevention 
in the fishing industry. For the Dungeness crab fleet, future work will include the collection of self-reported injury data to supplement these findings.

Missing data were not unusual in the dataset. The USCG documentation provided valuable information necessary to characterise nonfatal injuries; however, more information from fishermen regarding the context of the injury is needed for accurate characterisation of hazards. Future injury research should engage workers directly to obtain better data on their injury experience. Data quality would be improved by complete documentation of the injury by fishermen when reporting and thorough investigations by USCG personnel. Additionally, while AIS is a well-established clinical scale for trauma severity, it may not accurately reflect disability, time away from work, or reduced quality of life. These types of data, along with cost information, were not available for this study, but would improve the understanding of impact of these injuries. Lastly, exposure estimates for each work process were not available. Future work will estimate the time spent by the fishermen in each work process. Further investigation will allow for such estimates to be used to calculate risk of injury while performing various job tasks.

\section{CONCLUSIONS}

This study is the first step to understanding the burden of traumatic injuries of Dungeness crab fishermen. Further work is planned to collect self-reported injury data from the fleet to identify hazards and further refine the work process codes and exposure estimates. With these data, targeted and appropriate injury risk reduction interventions can be developed and tested with the fishermen and the fleet. This approach may be used to more accurately determine the incidence of injury in other fleets for better comparison.

\section{ACKNOWLEDGEMENTS}

The authors would like to acknowledge Kaety Jacobson for her thoughtful review and input during the preparation of this report.

\section{DISCLAIMER}

The findings and conclusions in this report are those of the author(s) and do not necessarily represent the views of the National Institute for Occupational Safety and Health.

\section{FUNDING}

This study was supported in part by the Grant Number U01 $\mathrm{OH} 010843$ funded by the Centres for Disease Control and Prevention/National Institute for Occupational Safety and Health.

\section{CONFLICT OF INTEREST}

The authors have no conflict of interest to disclose.

\section{REFERENCES}

1. Bureau of Labor Statistics. Injuries, Illnesses, and Fatalities: Census of Fatal Occupational Injuries (CFOI) - Current and Revised Data. Bureau of Labor Statistics, Washington, DC 2015.

2. Lincoln J, Lucas D. Commercial Fishing Fatalities - California, Oregon, and Washington, 2000-2006. MMWR 2008; 57: 426-429.

3. Lincoln JM, Lucas DL. Occupational fatalities in the United States commercial fishing industry, 2000-2009. J Agromedicine 2010; 15: 343-350.

4. National Marine Fisheries Service. Fisheries Economics of the United States 2012: Economics and Sociocultural Status and Trends Series. National Marine Fisheries Service, Silver Spring, MD 2014.

5. Hughes S, Goodman S, Antonelis K. Update of fishery employment estimates for workers on US commercial fishing vessels, West coast and Alaska (1994-2012), East coast (2000-2012) and Gulf of Mexico shrimp (2000-2012). Natural Resource Consultants 2013.

6. Hardin D, Lawrenson K. Operation Safe Crab. J Safety Security Sea 2010: 39-42.

7. Oregon Department of Fish and Wildlife. Commercial Crab Fishing [9 June 2015]. Available from: http://www.dfw.state.or.us/mrp/ shellfish/commercial/crab/index.asp.

8. Lucas DL, Kincl LD, Bovbjerg VE, Lincoln JM. Application of a translational research model to assess the progress of occupational safety research in the international commercial fishing industry. Safety Science 2014; 64: 71-81.

9. Bureau of Labor Statistics. Census of Fatal Occupational Injuries (CFOI): Definitions [27 May 2015]. Available from: http://www.bls. gov/iif/oshcfdef.htm.

10. U.S. Government Publishing Office. Notice of Marine Casualty and Voyage Records, 46 CFR § 4.05-1 2015 [14 October 2015]. Available from: http://www.gpo.gov/fdsys/granule/CFR-1998-title46-vol1/CFR-1998-title46-vol1-sec4-05-1.

11. Jensen OC, Stage S, Noer P. Classification and coding of commercial fishing injuries by work processes: an experience in the Danish fresh market fishing industry. Am J Ind Med 2005; 47: 528-537.

12. Lucas DL, Kincl LD, Bovbjerg VE, Lincoln JM, Branscum AJ. Wor$k$-related traumatic injuries onboard freezer-trawlers and freezer -longliners operating in Alaskan waters during 2001-2012. Am $J$ Ind Med 2014; 57: 826-836.

13. Jensen OC, Petursdottir G, Holmen IM, Abrahamsen A, Lincoln J. A review of fatal accident incidence rate trends in fishing. Int Marit Health 2014; 65: 47-52.

14. Dzugan J. The development and efficacy of safety training for commercial fishermen. J Agromedicine 2010; 15: 351-356.

15. Davis ME. Occupational safety and regulatory compliance in US commercial fishing. Arch Environ Occup Health 2011; 66: 209-216.

16. Bureau of Labor Statistics. Nonfatal Occupational Injuries and Illnesses Requiring Days Away From Work, 2013. Bureau of Labor Statistics, Washington, DC 2014.

17. Day ER, Lefkowitz DK, Marshall EG, Hovinga M. Utilizing United States Coast Guard data to calculate incidence rates and identify risk factors for occupational fishing injuries in New Jersey. J Agromedicine 2010; 15: 357-362.

18. Rosenman KD, Kalush A, Reilly MJ, Gardiner JC, Reeves M, Luo Z. How much work-related injury and illness is missed by the current national surveillance system? J Occup Environ Med 2006; 48: 357-365.

19. Kucera KL, Loomis D, Lipscomb H, Marshall SW. Prospective study of incident injuries among southeastern United States commercial fishermen. Occup Environ Med 2010; 67: 829-836. 